\title{
CIENCIA Y COLECCIONISMO EN CUBA EN EL SIGLO XIX
}

\section{Mercedes Valero González y Armando García González}

\author{
Centro de Historia de la Ciencia y la Tecnología, La Habana.
}

\section{RESUMEN}

En este artículo se brinda una panorámica de los museos y gabinetes que existieron en Cuba durante el siglo XIX, describiéndose las características y funciones, así como las causas que hicieron desaparecer a algunos de ellos. También se destaca la continuidad asumida por el coleccionismo científico desde el siglo XVIII y su mayor institucionalización en el XIX. Asimismo se intenta dar una cronología muy general sobre el desarrollo de los museos en Cuba, teniéndose en cuenta la perdurabilidad o no de dicha institucionalización. Los autores lamentan la escasez de trabajos que traten el tema y la ausencia total desde el punto de vista comparativo.

\section{SUMMARY}

In this article a panoramic is exposed about museums and cabinets which existed in Cuba during the nineteenth century, describing functions and characteristics as well as the causes that made some of them disappear. It is also shown the continuity, asumed by the scientific collection over since major nationalized-institute in the nineteenth century. It is likewise intended to give a general and complete chronology about the development of museum in Cuba, taking into account the lasting-long or not of such institute. The authors regret the work shortege that considers the subject and total absence from the comparative standpoint.

Las evidencias del coleccionismo científico en Cuba se remontan a la segunda mitad del siglo XVIII, coincidiendo con el auge que en ese y otros sentidos desencadenó el movimiento político, social y cultural de la Ilustración. En la Isla, como en otras partes del mundo, este proceso de coleccionar muestras relacionadas con las ciencias, debió estar precedido por el interés personal de quienes se motivaron en las colecciones de arte y más tarde con diversos objetos raros e interesantes de carácter científico. Pero no tenemos constancia hasta el momento de personas que se dedicaran a esta tarea antes de aquella fecha. Es posible también que, al igual que en otros muchos países, el coleccionismo científico conformó primero los gabinetes de curiosidades particulares con una abigarrada muestra de exponentes y pasó luego a formar parte de instituciones a las que en ocasiones se les denominó Museos, como se había 
efectuado desde la antigüedad. Naturalmente que la concepción que se tenía entonces de los museos, no coincide con la actual, donde, por lo regular, los exponentes tienen valor histórico, científico o museable, mientras que en los siglos anteriores lo «curioso» o novedoso predominaba. Ello no obsta para que entre las colecciones se encontrasen algunas que reunían aquellos requisitos, resultando verdaderamente importantes.

Las funciones que realizaron estos museos y gabinetes - no haremos distinciones salvo que sea necesario-, tanto particulares como institucionales, siguieron por tanto la misma evolución que en los países europeos. Atraer al público, pero también enseñar y, por supuesto, constituir una forma de representar el adelanto alcanzado por los pueblos que los exhibían. Los museos y gabinetes del mundo se enriquecieron ostensiblemente mediante la compra de colecciones a individuos aficionados y también gracias a las colectas que los científicos, de manera individual o a través de las expediciones científicas, efectuaron a diversos países y regiones. Entre estas últimas pueden mencionarse las llevadas a cabo por España a los reinos de Perú y Chile (1777-1788), al Nuevo Reino de Granada (1783-principios del XIX), al Reino de Nueva España (1787) y a Cuba y otras islas (1896-1802), que conformaron herbarios y recolectaron otras muestras vegetales, así como especímenes animales y objetos de diversa índole, muchos de los cuales fueron a parar al Jardín Botánico y al Gabinete de Historia Natural de Madrid. De la misma manera, estas expediciones permitieron la fundación de cátedras, así como la confección de obras científicas, algunas de las cuales quedaron, sin embargo, sin publicar debido, entre otras cosas, a problemas económicos.

De tales expediciones, dos se relacionaron más directamente con Cuba. La visita de Martín Sessé y del conde de Mopox en uno y otro caso, cumplieron esas funciones, si bien no llenaron las expectativas de los criollos en cuanto al desarrollo efectivo de la Isla, pues no se llevaron a cabo los propósitos originarios (la fundación de un jardín botánico, el canal de Güines, etcétera). No obstante, constituyeron estímulos dentro de la comunidad nacional, preocupada por el desarrollo científico y cultural de Cuba en esa época. De modo que la conformación de gabinetes en la Isla está relacionada íntimamente con la de España, que entonces era su metrópoli. Así, la constitución del Gabinete de Historia Natural en Madrid, en 1752, bajo el reinado de Fernando VI, motivó el interés por recolectar piezas de esa naturaleza que se encontraran en las colonias. Algunas de esas piezas ya eran obtenidas por diversos particulares a través de intercambio con otras personas de distintas ciudades, como es el caso, por ejemplo, de los trámites realizados por Pedro Franco Dávila para lograr algunas de La Habana, Veracruz y Buenos Aires ${ }^{1}$. Si bien el aludido Gabinete de

\footnotetext{
1 Véase al respecto «Ref. 33 Carta de D. José Lasquetti a Pedro Franco Dávila, y otra de 5 de febrero de 1754 contestando a Dávila, a la del 1 de enero, donde se le acusa recibo de un cajón con determinadas colecciones. Le habla de que de Veracruz, La Habana y Buenos Aires, espera le envíen algunas cosas, y que él remitirá particularmente petrificaciones». Museo de Ciencias Naturales de Madrid.
} 
Historia Natural - primero a cargo de Antonio Ulloa y luego de Eugenio de Reigosa- no llegó a adquirir relevancia, y degeneró lentamente hasta $1776^{2}$, constituyó un importante precedente del coleccionismo científico español y cubano, pues en un principio se nutría de las curiosidades remitidas de las colonias y de los intentos posteriores por comprar las que estaban en poder de particulares ${ }^{3}$.

Tal fue el caso del gabinete de Ciencias Naturales constituido en La Habana por Antonio Parra, desde 1763 hasta 1793, y vendido al de Madrid, luego de previa correspondencia entre este personaje y los directores de esta última institución: Dávila y José Clavijo. La colección de Parra estaba compuesta fundamentalmente por peces, crustáceos, «petrificaciones marinas» como corales, espongiarios, asi como algunos cuadros y muebles, entre otros. Pero lo significativo es que dicho gabinete representó, mientras se conformaba y estuvo expuesto al público, una muestra del desarrollo alcanzado por las ciencias y las artes en la ciudad de La Habana en medio de los debates que a fines del siglo XVIII se producen en torno a dicho desarrollo, ante las críticas opiniones de cubanos y europeos y en cuyo fondo se observan las primicias del despertar de la conciencia nacional.

Tanto esta labor de Parra, como su actividad botánica recolectando y enviando semillas y plántulas cubanas para ser aclimatadas en España, y la de otros aficionados residentes en Cuba como Pedro Lacomte y Mariano Espinosa, tienen que ver también con los intereses que en igual sentido se producen en la península luego de la constitución del Real Jardín Botánico de Madrid, fundado en el Soto de MigasCalientes en 1757, donde se conjugan la preocupación por la enseñanza de ciencias como la botánica, con la publicación de obras y la realización de expediciones a diferentes colonias en busca de piezas de historia natural para aquella labor, así como para nutrir el supracitado Gabinete ${ }^{4}$. De la misma manera, están en consonancia con los intereses de algunos grandes hacendados y comerciantes cubanos que a partir de 1793 se aglutinaron para formar la Sociedad Económica de Amigos del País y de La Habana, y entre cuyos objetivos se encontraban los de crear cátedras de botánica y

2 Ulloa propuso al rey la fundación del gabinete y fue su primer director. Se compró una casa donde situarlo, se trajeron especialistas de varios países para ocupar diferentes cargos y se adquirieron colecciones de instrumentos, antigüedades, etcétera. Tres años después de fundado, Ulloa renuncia y le sustituye Reigosa. A su muerte las colecciones fueron a parar a un almacén, hasta 1776. CALATAYUD, M. A. (1986) «Antecedentes y creación del Real Gabinete de Historia Natural de Madrid». Arbor. Madrid, t. CXXIII, Núm. 482, pp. 9-33; BARREIRO, A. J. (1944) El Museo Nacional de Ciencias Naturales. Madrid, Consejo Superior de Investigaciones Científicas, «José de Acosta», p. 14.

3 Véanse diversas referencias sobre envíos y peticiones de «producciones naturales» de La Habana y otras ciudades: Ref. 68-1777, julio 20. París; Ref. 118-1773, febrero 22; Ref. 142-1773, octubre 26; Ref. 46-1777.

4 Para más detalles, véase a GARCía GonZÁleZ, A. (1989) Antonio Parra en la ciencia hispanoamericana del siglo XVIII. La Habana, Editorial Academia; así como del mismo autor (1995) «La obra botánica de Antonio Parra». Asclepio. Madrid, Vol. XLVII, Fasc. 2, pp. 143-157. 
química, laboratorios, museos y bibliotecas, a fín de impulsar el desarrollo científico de Cuba a través de la agricultura y de la enseñanza.

Esto explica, en parte, la fundación, ya en el siglo XIX, de los primeros «museos» dedicados a las ciencias naturales que se constituyen en la Isla. Pero antes de referirnos a ello, digamos que el coleccionismo científico no sólo siguió esta línea de intereses particulares e instituciones de carácter educativo general, sino también a través de otras más constreñidas a la enseñanza, como fueron por ejemplo las Universidades, Institutos, Colegios y Seminarios. Naturalmente que tampoco podrían considerarse como verdaderos museos las colecciones que estas instituciones conformaron, por cuanto se referían más bien a conjuntos de instrumentos con función docente pero, con el tiempo, se ampliaron considerablemente para constituir gabinetes a los que en ocasiones se les dio el nombre también de museos.

En este sentido Cuba, como España y otras partes del mundo, muestran esa continuidad, donde la acumulación de objetos tenía como base y estaba en dependencia de las ciencias que requerían de tales objetos para su demostración práctica, como eran la física y la astronomía y más tarde la geología (mineralogía), medicina, química, zoología, botánica y otras. En realidad, si exceptuamos el Museo de la Sociedad Económica de Amigos del País y el de la Real Academia de Ciencias Médicas, Físicas y Naturales de La Habana y las colecciones de individuos particulares, la mayor parte de los gabinetes y museos del decimonónico cubano estuvieron en función de la enseñanza.

En el caso de la Isla no tenemos constancia de que en la Real y Pontificia Universidad de San Jerónimo de La Habana, fundada en 1728, existiesen durante el siglo XVIII colecciones de tales instrumentos, y es poco probable, teniendo en cuenta que la enseñanza, como revelan algunos historiadores, era teórica en lo fundamental. Como es el caso de la medicina, por ejemplo, que se comienza a explicar de manera práctica en los hospitales. Así, digamos, en el Hospital Militar de San Ambrosio, donde se produce la reapertura del curso de Cirugía en $1797^{5}$, se empleaba, aunque escaso, determinado instrumental quirúrgico allí radicado, aunque sin el apoyo de otras piezas que serán incorporadas en el siglo XIX , como después veremos.

También la física tuvo determinado apoyo instrumental para su explicación práctica. Es posible que desde fines del siglo XVIII se incorporaran instrumentos a la enseñanza de esa disciplina en el Seminario de San Carlos y San Ambrosio, pero hasta ahora carecemos de evidencia documental. Las que conocemos se refieren a

\footnotetext{
5 La reapertura de este curso estuvo a cargo - gracias a las gestiones del Intendente del Ejército José Pablo Valiente-del licenciado Francisco Javier de Córdova y Torrebejano, Cirujano Médico de la Real Armada y Mayor por S. M. de los Hospitales del Ejército de La Habana. Ver CóRdovA, F.X. (1797) Oración inaugural en elogio de la Cirugía, y para dar principio al curso teórico de esta facultad, que por disposición del Señor visitador ó intendente del Exército de esta Isla va á abrir nuevamente en el Real Hospital de San Ambrosio de esta Ciudad el día 6 de Abril de 1797. Havana, Imprenta de D. Esteban Boloña.
} 
principios del siglo XIX y debieron servir de base a las explicaciones de sus primeros profesores Félix Varela, José Antonio Saco y José de la Luz y Caballero.

La continuidad en ese sentido se observa asimismo en relación con la química y la botánica, si bien ninguna de estas materias tuvo su arranque en el siglo XVIII, sino en la centuria siguiente. Los intentos de crear en el siglo de las luces un laboratorio de química y un jardín botánico se quedaron en proyectos y baldíos esfuerzos. De manera que, salvo el de Parra, ningun gabinete parece haberse constituido al respecto.

\section{INSTITUCIONALIZACIÓN DE LOS PRIMEROS MUSEOS Y GABINETES EN CUBA.}

La primera mitad de la centuria decimonónica cubana se caracterizó, por tanto, por los intentos - a veces fructíferos-de institucionalizar esos gabinetes o museos, labor en la que se enfrascaron algunos miembros de la Sociedad Económica de Amigos del País, de La Habana, apoyándose en representantes del gobierno, como los Intendentes Alejandro Ramírez y Claudio Martíez de Pinillos, conde de Villanueva. Entre aquellos hombres se encuentran tanto figuras españolas como cubanas, e involucraron a veces italianos y franceses, residentes en la Isla por ese entonces.

Un claro ejemplo de ello se halla en el coleccionismo vinculado con la botánica y la agricultura, en relación con el Jardín Botánico y la Institución Agrónoma de La Habana; así como con la química, la anatomía, la cirugía y la obstetricia, en colaboración con el Museo Anatómico y el Instituto de Investigaciones Químicas de esa misma ciudad. Algo parecido sucedió con las colecciones particulares de zoología y mineralogía que conformaron el Museo de la Sociedad Económica. Naturalmente que algunas de estas figuras no se ciñeron a un solo tipo de colección, sino que incluyeron, dentro de su actividad, exponentes de diferente naturaleza. No faltaron tampoco las que se mandaron a realizar o enriquecer expresamente para un gabinete determinado, como fue al parecer, el de modelos de cera encargados al italiano José Chiappi por el Intendente Ramírez

En el primero de estos casos, diremos que el coleccionismo botánico se caracterizó fundamentalmente por la creación de herbarios y colecciones de semillas y maderas, tanto nacionales como extranjeras, que se obtuvieron mediante recolección en expediciones, intercambio y compra a particulares.

6 Según El Tío Bartolo. Habana, Imprenta Liberal a cargo de D. Tiburcio Campe, 1820-1821, No. 53, p. 212, Ramírez, precedido del acuerdo de la Sociedad Económica, propuso comprar la colección de los Chiappi, fijando un precio de 18.000 pesos; por el cual los italianos trabajaron durante dieciocho meses. Como el primero, una vez terminada dicha colección, creyó excesivo su precio, se negó a comprarla y Chiappi indignado, la destruyó. Relato que debe valorarse teniendo en cuenta que la publicación arremete continuamente contra Ramírez por su «mala» administración. 


\section{MERCEDES VALERO GONZÁLEZ Y ARMANDO GARCÍA GONZÁLEZ}

Entre las personalidades que realizaron labor botánica en Cuba durante el pasado siglo se encuentran José Antonio de la Ossa, Ramón de la Sagra, Adolfo Sauvalle, Manuel Gómez de la Maza y otros. El primero estuvo al frente del Jardín Botánico desde su fundación en 1817 y recolectó plantas en La Habana y sus alrededores, que envió a científicos célebres como Adolfo de Candolle, y que a su vez utilizó para su obra Flora Havanensis, desgraciadamente perdida.

Sagra, por su parte, sustituyó a de la Ossa haciéndose cargo del Jardín en 1823 y de la cátedra de botánica en 1824 , fecha en que se creó esta última. Es una de la figuras donde se concreta en su mayor expresión el interés por el coleccionismo científico, en función del adelanto de los pueblos a través de su educación y desarrollo económico y cultural. Una de sus primeras proyecciones en ese sentido fue la organización de la cátedra científica con una escuela agrícola, donde estuvieran presentes colecciones de especies de plantas útiles. Para esto debió apoyarse en los herbarios realizados por de la Ossa, que él enriqueció, además de conformar otros nuevos. Igualmente estableció contactos e intercambio de semillas y plantas con personalidades de distintas instituciones científicas del mundo ${ }^{7}$, como el aludido Candolle, Mercier, Mericand, Adrian de Jussieu, Descaines, Benthan y otros que describen plantas de Cuba.

Esta labor recolectora y clasificatoria de Sagra se efectuó también gracias a la colaboración de personas radicadas en La Habana y el interior de la Isla, como el botánico camagüeyano Tomás Pío Betancourt, Justo Velez, Desiderio Herrera, el presbítero Ramón de la Paz y Morejón, Sebastián Bonani, Emilio Lanier, Antonio Reynoso, Manuel de Monteverde, Manuel Donoso, Hilario de Cisneros y otros.

En relación con la agricultura, Sagra se interesó además por los instrumentos aratorios y en general agrícolas. De estos llegó a existir una determinada colección de la Institución Agrónoma de La Habana, fundada en 1828, con el fin de facilitar la enseñanza práctica de los cultivos. Instrumentos que fueron adquiridos en Europa y Estados Unidos (Filadelfia) a excepción de algunos construidos en esta propia institución ${ }^{8}$. En cierta medida seguiría su tradición años más tarde, en 1881, la Escuela de agricultura del Círculo de Hacendados. Esta institución contó con un gabinete de agricultura que mostraba las máquinas e instrumentos empleados en los cultivos cubanos, y en general en las industrias rurales, los cuales eran usados por los catedráticos de agronomía para demostrar su utilización y procedimientos en el campo de experimentación de la Escuela. Ésta poseyó además un gabinete de historia natural,

\footnotetext{
7 Su labor le valió ser considerado Miembro Correspondiente (Corresponsal) de diversas instituciones, como las Academias de París, Ginebra, Londres, Moscú, Filadelfia, New York. Véase VALERo GonZÁLEZ, M. (1988) «El Jardín Botánico de La Habana en el siglo XIX». Anuario, 1. Centro de Estudios de Historia y Organización de la Ciencia. La Habana, Academia de Ciencias , pp. 248-271.

8 Puig-SAmper Mulero, M. A. y VAlero GonzÁlez, M. (1996) Historia del Jardín Botánico de La Habana. Aranjuez, Editorial Doce Calles (en prensa).
} 
donde los alumnos podían contemplar las colecciones de aves y otros animales disecados, así como laboratorios de física y de química, nutridos a partir de colecciones anteriores ${ }^{9}$.

Sagra llevó a cabo asimismo una labor recolectora de especímenes animales -aves, reptiles, peces, insectos, moluscos-, que abarcó también donaciones de personalidades como Felipe Poey y otras, que menciona en su Historia Física, Política y $\mathrm{Na}$ tural de la Isla de Cuba. Tales muestras le sirvieron tanto para la confección de esta monumental obra, como para enriquecer el Gabinete de Historia Natural ${ }^{10}$ e intercambiar especímenes con personas e instituciones. Esta última labor la intensificó durante su visita a los Estados Unidos de Norteamérica en 1835, donde por espacio de cinco meses, observó y se relacionó con las colecciones recogidas por diferentes personalidades, gabinetes y museos de ese país ${ }^{11}$.

Entre estos últimos pueden mencionarse los que se encontraban en el Liceo de Historia Natural de New York, el Ateneo de Filadelfia, que se destaca entre otros aspectos por la existencia de un herbario que contenía 2.500 especies, el gabinete situado en esa propia ciudad, en la Sociedad Filosófica, y el de la Academia de Ciencias Naturales, sorprendente por sus colecciones de plantas y animales, aunque con cierto desorden, según Sagra. También en Filadelfia tuvo la oportunidad de visitar las colecciones existentes en el Instituto Franklin y la Sociedad de Horticultura. Igualmente en otras ciudades como Baltimore, por ejemplo, visitó museos, como el del Colegio de Medicina, gabinetes de física, laboratorios de química, etcétera. Constituyó la ciudad de Washington una de las mayores atracciones para Sagra, por la considerable colección de modelos existentes en la Oficina de Patentes, sobre todo máquinas agrícolas. En Boston, también tuvo la oportunidad de observar las magníficas colecciones en la Sociedad de Historia Natural, en el museo gabinete de instrumentos de física y de química, así como de piezas anatómicas. En ese propio recinto visitó el jardín y la escuela de botánica.

De regreso a Filadelfia mostró nuevamente su interés por las colecciones, pero en esta oportunidad por aquellas que estaban en manos de particulares, con los cuales intercambió muestras de su colección cubana. Entre las especies que le fueron ofrecidas para dicho intercambio estaban plantas de herbario, aves, insectos, conchas de moluscos, fósiles, minerales, pudiendo obtener, a pesar de su reducida colección cubana, valiosos ejemplares que empaquetó y envió a La Habana, con destino futuro

9 Para más detalles sobre esta institución, véase a FERNÁNDEZ PRIETO, L. El Círculo de hacendados en la formación de ingenieros agrónomos en Cuba, la Escuela de agricultura: 1881-1891 (monografía inédita).

10 Véase, por ejemplo, el envío de aves realizado en 1825. Archivo Nacional de Cuba. Fondo Intendencia, Leg. 312, No. de orden 33, 1825.

11 Sagra, R. de la (1835) Cinco meses en los Estados Unidos de la América del Norte, Diario de Viaje. París, Pablo Renouard. 
al Real Gabinete de Historia Natural de Madrid. Tanto las colecciones existentes en manos de estos particulares, como de las instituciones, no solo contemplaban tales muestras sino instrumentos y otros variados objetos, pertenecientes a Estados Unidos pero también a otras regiones de América y Europa.

Por lo antes dicho se comprende que el coleccionismo realizado por Sagra no quedó recogido de forma institucionalizada en Cuba, como lo fue por ejemplo con Felipe Poey. Éste, quien ya desde antes colectaba minerales, así como especímenes animales (peces, insectos), había donado al propio Sagra e incluso llevado ejemplares de la década de los veinte a George Cuvier para que los estudiase. En 1838 ya Poey poseía una importante colección que donó al recién creado Museo de la Sociedad Económica de Amigos del País, de La Habana. A pesar de ello y del aporte que hicieron personalidades como José María Zamora, Ramón de la Paz y Morejón y el propio Poey que ocupó la dirección del mismo, lo cierto es que se vio falto de recursos económicos, y acabó pasando a la Universidad a fines de la década de los cuarenta ${ }^{12}$. La creación de este museo tenía también un fin educativo y como muestra del desarrollo alcanzado por la Isla, pero evidentemente, gran parte de los integrantes de la Sociedad, constituida por hacendados y comerciantes, no mostraron mucho interés, preocupados más por las ciencias vinculadas directamente con la agricultura cañera y general, y por tanto con sus intereses económicos.

De esta manera, los conflictos económicos serán determinantes en la corta supervivencia de algunas de estas instituciones. Algo parecido sucedería con el Museo Anatómico y el Laboratorio de Química. El primero, fundado en 1823, comenzó por adolecer de un local adecuado hasta que parcialmente se resolvió el asunto con los arreglos efectuados en una de las salas del Hospital Militar de San Ambrosio. Independientemente de cómo se manejaron los fondos ${ }^{13}$, las reformas realizadas, tanto para éste como para el laboratorio químico, contemplaban la contratación de médicos y especialistas, como fueron el italiano José Tasso, el francés Auguste Louis Saint André, el español Francisco de Paula Alonso y Fernández y los cubanos Tomás Romay y Nicolás José Gutiérrez entre otros. Todo ello, así como la compra de «órganos de madera desmontables», piezas de cera e instrumentos quirúrgicos en ciudades como París y Florencia, la confección de cuadros pintados, etcétera, requirió un importante presupuesto económico, que luego faltó para sostener y ampliar el museo a partir de 1834.

12 Hubo un intento por reactivarlo en esa década. En 1847 y 1848 presentaba un estado lamentable, según las actas de las Memorias de la Sociedad Económica... de esos años, y en 1849 se disuelve recogiendo Poey sus pertenencias para enviarlas a la Universidad donde era catedrático de zoología.

13 Un juicio desfavorable de cómo se emplearon cuantiosas sumas en esos arreglos aparece en El Tío Bartolo... Opus cit., No. 36, pp. 142-145; No. 37, pp. 146-149; No. 38. pp. 154-157 y No. 53, pp. 210-213. Los primeros arreglos de locales para el museo se realizaron de 1817 a 1820, luego se repitieron en 1823 y 1834. Aquellos bajo la protección de Ramírez, y los últimos, del conde de Villanueva, Martínez Pinillos. 
Pese a que el museo se enriqueció con donaciones de personalidades ya mencionadas y de otros médicos de la época, llegándose a tener allí además esqueletos y huesos naturales, así como objetos obtenidos en operaciones quirúrgicas, esa función se encaminó hacia un fin educativo práctico, pues en él se impartieron clases y crearon cátedras de anatomía, cirugía y obstetricia; asimismo se llevaron a cabo disecciones de cadaveres y se atendieron a enfermos y muertos de la epidemia de cólera de 1833. Debido a esta epidemia, entre otras razones, se reactivó el museo a partir del año siguiente, luego de grandes arreglos que contemplaron la construcción de un anfiteatro y la ampliación del propio museo, todo en el referido Hospital de San Ambrosio y con el apoyo, como ya dijimos, del conde de Villanueva.

El Museo Anatómico tuvo su mayor esplendor hasta 1842, fecha en que se llevó a cabo la secularización de la Universidad, si bien continuó funcionando durante la década del cincuenta, hasta que, con las reformas de 1863, llevadas a cabo en dicha Universidad, todas sus piezas pasaron a formar parte de los gabinetes de esta última institución docente ${ }^{14}$. La falta de recursos económicos, fue decisiva también en estos casos. Su papel significativo en la enseñanza práctica de esas ciencias quedó sin embargo como un importante precedente de la labor educativa -que según estiman algunos debe caracterizar a los museos- en un momento en que la enseñanza de esas ciencias era eminentemente teórica en la Universidad.

A pesar de todo ello, la comunidad científica en Cuba prosiguió con el anhelo de poseer un museo de carácter científico que llenara sus espectativas. Diversas figuras continuaron, por tanto, recolectando y conformando gabinetes personales de ciencias naturales. Así, naturalistas como Francisco Jimeno, Manuel Presa, Rafael Arango y Molina, el alemán residente en la Isla, Juan Cristóbal Gundlach, y otros conforman colecciones animales y minerales que estudian y envían a Exposiciones Internacionales, al tiempo que las utilizan para elaborar catálogos y otras obras.

Las condicones políticas y socioeconómicas en Cuba no parecen ser las más adecuadas para la institucionalización en la década del sesenta, donde se gesta y desencadena la Guerra de los Diez Años. Pese a ello se crea en 1861 la Academia de Ciencias Médicas, Físicas y Naturales de la Habana, gracias al esfuerzo mancomunado de científicos cubanos y españoles, residentes en la Isla. Esta corporación, desde sus inicios, se propuso crear un museo de ciencias naturales, y para ello recolectó diversas piezas que quedan en manos de los miembros, por carecer la Academia de un local para su instalación. No fue hasta 1874 cuando obtuvo el salón alto del convento de San Agustín (la Academia ocupaba parte de la planta baja), luego de arduos intentos y gestiones con el gobierno insular. Aunque el permiso para obtener el local y la ampliación del mismo databa de 1873, otra vez la falta de recursos económicos fue

14 Véase Memorias de la Universidad de La Habana. Habana, Imprenta del Gobierno y de la Capitanía General, 1865. 
un factor decisivo. En este año la Academia sólo recibió como ayuda del gobierno 41.66 pesos $^{15}$. Debe tenerse en cuenta, por otra parte, que el país se encontraba envuelto en la guerra. De modo que dicha institución debió recurrir a otras fuentes, como donaciones personales, dinero de los censos y sobre todo del producto de un concierto benéfico, para acometer tales arreglos. Por fin en 1874 se creó en el salón de la planta baja el «museo indígena» y la biblioteca, pasando al salón alto la sala de sesiones.

El museo de la Academia llegó a reunir colecciones de animales y plantas (herbarios, el más relevante de ellos fue el de Sauvalle), fósiles, objetos de cera, minerales, material osteológico y arqueológico, donados por figuras como Felipe Poey (peces y fósiles), Avelino Barrera (aves), Arango y Molina (moluscos), Gundlach (aves, etcétera), Luis Montané y Carlos de la Torre (material osteológico aborigen, objetos arqueológicos); estos últimos exponentes, como resultados —en lo fundamental-de las expediciones efectuadas por estas figuras a diversas regiones de Cuba y otras islas. Pueden mencionarse en ese sentido las llevadas a cabo por Montané a Sancti Spiritus en 1888 y a las regiones central y oriental de Cuba en 1892. Además de todas estas piezas, el museo contó con una sección de teratología (fetos, tumores, animales y vegetales con deformaciones congénitas), objetos e instrumentos de todo tipo (microscopios, barómetros, sifones), así como fotografías, cuadros y bustos. También existían colecciones formadas con plantas de Puerto Rico, maderas útiles del Canadá, etcétera, fruto de las relaciones de intercambio y visita de personalidades e instituciones con las cuales la Academia mantenía vínculos de colaboración ${ }^{16}$.

El museo de la Academia sirvió en ocasiones, además por la variedad, riqueza y estado de sus colecciones, para apoyar la enseñanza universitaria, debido a la escasez y condiciones desfavorables en que también por falta de recursos se encontraban las colecciones en el convento de Santo Domingo, donde radicaba la Universidad.

\section{GABINETES Y MUSEOS EN LOS CENTROS DE ENSEÑANZA.}

Como hemos visto anteriormente, el gabinete de Historia Natural de la Universidad de La Habana debió constituirse en torno a 1849 ó $1850^{17}$, aunque poseyera al-

\footnotetext{
15 ORTEGA. O. (1984) «Historia de la sede de la Real Academia de Ciencias de La Habana». Conferencias y Estudios de Historia y Organización de la Ciencia. No. 38.

16 Para más detalles véase a GARCÍA GonZÁlEZ, A. (1994) Historia del Museo de la Real Academia de Ciencias Médicas, Físicas y Naturales de La Habana. La Habana, Editorial Academia.

17 Esto se realizó por esta fecha, siendo rector el doctor Manuel Gómez Marañón. Éste ejerció su función desde abril de 1848 hasta 1852; con un breve periodo de nueve meses (febrero a noviembre de 1849) en que ejerció como tal, de manera interina, Bonifacio Quintín de Villaescusa. Memorias de la Universidad, Op. cit., 1866, p. 109.
} 
gunas piezas desde 1842 - si se tiene en cuenta lo ya dicho respecto a la creación de la cátedra de Historia Natural con la secularización-, gracias a las reformas educativas de este último año ${ }^{18}$ y la incorporación de Felipe Poey al frente del gabinete y de la cátedra, conjuntamente con Emilio Auber ${ }^{19}$. A las colecciones aportadas por Poey debieron añadirse las de otros profesores y colaboradores, así como las conseguidas por la propia Universidad, y también instrumentos, maquinarias, objetos y sustancias obtenidas posteriormente para las clases de física, química, anatomía y otras ciencias, con las cuales se crearon los gabinetes respectivos. Los mismos se habían orientado con el Plan General de Instrucción Pública para la Isla de Cuba en 1858, cuyo capítulo quinto manifestaba, entre otras cosas, que el gobierno cuidaría del «establecimiento de museos y archivos formando un reglamento para ello», así como de que «la Universidad tendría los correspondientes laboratorios, gabinetes, museos, colecciones y demás dependencias de este orden, necesarias para la enseñanza según determine el reglamento» ${ }^{20}$.

En efecto, con las nuevas reformas realizadas en $1863^{21}$, se terminó de conformar el gabinete de Historia Natural, que continuó bajo la dirección de Poey ${ }^{22}$. Las colecciones de mamíferos, aves, reptiles, peces, moluscos, insectos, zoofitos, fósiles, minerales y plantas recibieron determinados incrementos y renovaciones de especímenes (que iban destruyéndose) en los años siguientes. Fue el que mantuvo mejor estado de conservación y quizás el más rico de los gabinetes de la Universidad. El gabinete anatómico, por su parte, se conformó con las piezas de cera, instrumental de cirugía y obstetricia y otras muestras procedentes del Museo Anatómico del Hospital Militar de San Ambrosio, a las que se incorporaron las piezas de cartón desmontables relativas a la anatomía humana y animal, que constituían la colección denominada «clástica» del doctor Auzoux ${ }^{23}$.

$18^{\circ}$ En 1842, bajo el gobierno de Gerónimo Valdés se realizaron las reformas, cuyos Estatutos y Reglamento fueron aprobados por Real Orden del 24 de agosto del citado año. Al efecto se incorporaron las asignaturas de matemáticas, física, química, historia natural, geografía y otras, en las facultades mayores de medicina, cirugía y farmacia, y jurisprudencia. Memorias de la Universidad, Op. cit., 1865, p. 6.

19 Por este plan eran directores del museo los catedráticos de mineralogía y botánica, y de zoología y anatomía comparada, Emilio Auber y Felipe Poey, y como ayudantes conservadores Fernando Layunta, Eladio Carreño y Pedro A. Auber. Memorias de la Universidad, Op. cit., 1866, p. 20.

20 Plan General de Instrucción Pública de la Isla de Cuba, 1858. Archivo Nacional de Cuba, Caja 208, Núm. 38.

21 Por Real Decreto del 15 de julio de 1863 quedan como facultades la de medicina, farmacia, derecho y teología y las de filosofía, letras y ciencias exactas, físicas y naturales. Las asignaturas de física química e historia natural correspondían a la sección de ciencias, y las de historia, geografía universas y literatura latina a la de artes. Por esta misma orden se crearon además los Institutos de Segunda Enseñanza. Memorias de la Universidad, Op. cit., 1865, pp. 6-7.

22 Con este plan, la dirección del gabinete quedó en manos de Felipe Poey; y la plaza de conservador en las de Pedro Alejandro Auber. Ibidem, 1866, p. 20.

23 Comprada tal vez a este personaje. 
El gabinete de química se nutrió de los aparatos y útiles que procedieron del entonces suprimido Instituto de Investigaciones Químicas, creado en 1848, solicitando asimismo la Universidad, «varias cajas de química» encargadas al extranjero por la Real Junta de Fomento, y que existían en el Depósito Mercantil ${ }^{24}$. Por su lado, el de física contó con aparatos y maquinarias, y el de farmacia tuvo además de éstos, sustancias y medicamentos.

Todo ello, sin embargo, no llenaba la función educativa que debían tener tales gabinetes, por lo que la Universidad planteó la necesidad de adquirir y ampliar locales, comprar muebles y colecciones, así como contratar personas para atenderlos. De ahí que demandara del gobierno importantes sumas, sobre todo teniendo en cuenta el estado ruinoso en que se encontraba el viejo convento de Santo Domingo, sede de la Universidad desde 1728. Esto explica por qué, por ejemplo, solicitó el rectorado 60.000 pesos para obtener una extensión de cien metros en el glásis de las murallas para construir allí el edificio de la Universidad, como debía corresponder «a la importancia de una provincia como la Isla de Cuba». Así también se explica la petición de dinero para arreglar el salón alto de la azotea con el fin de establecer allí el laboratorio de química, la petición de un «local decente apropiado» para las explicaciones de las clínicas que se daban en el hospital de San Felipe y Santiago, y el aumento de las gradas de la cátedra de anatomía, por lo reducido del local, que impedía que pudiesen colocarse convenientemente todos los alumnos concurrentes a ella. También solicitaron plazas como la de «modelador» para atender las piezas del gabinete anatómico e incluso la posibilidad de aumentar éstas e igualmente otra, de ayudante, para el cuidado y conservación de los gabinetes. Del mismo modo, se requerían muebles y estantes, a fin de acondicionar tales aulas, laboratorios y gabinetes. Para ello se calcularon y sometieron al gobierno los presupuestos parciales a fin de atender las necesidades de los gabinetes de la Universidad, que ascendían a poco más de veinte mil pesos ${ }^{25}$.

La Universidad no contó, sin embargo, con el dinero suficiente y los arreglos que se realizaron fueron mínimos. La asignación anual impuesta por el Reglamento del Plan de Reformas de 1842 era de 400 pesos, pero en 1863 se redujo a la mitad, por lo cual el rectorado dejó consignado que «el museo de la Universidad necesita mejor local, muebles apropiados, y una asignación más crecida» ${ }^{26}$. Pero no se le llegó a dar solución al asunto.

Después de la Guerra de los Diez Años, la Universidad ofrecía condiciones lastimosas. Al hacerse cargo del rectorado de la misma en 1879 el doctor Nicolás José Gutiérrez, señalaba las condiciones precarias en que se encontraba el edificio, con las

\footnotetext{
24 Ibidem, 1865, pp. 14-15.

25 La cifra para los gabinetes de farmacia, anatomía física y química e historia natural, y armarios, ascendía exactamente a $\$ 20$. 101, 67. Ibidem, 1866, p. 5-6.

26 Ibidem, 1866, pp. 19-22
} 
aulas pequeñas, mezquinos los museos, al igual que los laboratorios de física y química y la biblioteca, la escasez de aparatos y maquinarias para la enseñanza de esas ciencias, el efecto funesto del polvo y la humedad, y el estado ruinoso del edificio en general ${ }^{27}$. De manera que el profesor Juan Vilaró debió pedir permiso a la Academia para llevar a sus alumnos a ella y explicarles sus clases de ciencias naturales con las colecciones de esta última institución.

Al propio tiempo, sin embargo, los gabinetes de los Institutos de Segunda Enseñanza mostraron un relevante desarrollo en la segunda mitad del siglo XIX, especialmente los de La Habana y Matanzas. Estos Institutos, creados en cada una de las seis provincias por las reformas de 1863, llegaron a tener importantes colecciones de ciencias naturales ${ }^{28}$. En el primer caso, además de los gabinetes de física y química, se constituyeron los «museos» de historia natural: uno con exponentes de diversos coleccionistas y otro formado por las colecciones compradas al naturalista alemán Juan Cristóbal Gundlach, en 1892. Para tales colecciones, representadas por mamíferos, aves, reptiles, anfibios y crustáceos, fue necesario hacer algunas modificaciones estructurales en el Instituto entre los años 1893 y 1894, habilitando un local especial, con vistosos muebles y armarios donde se colocaron las piezas zoológicas ${ }^{29}$. El Instituto de Matanzas siguió más o menos la misma evolución, partiendo de colecciones y donaciones particulares, aunque también obtuvo por compra instrumentos para sus gabinetes.

El de Santa Clara adquirió cierta relevancia, sin embargo, de forma más tardía, a partir de 1882. Como el de La Habana, estuvo representado por colecciones de física, química, agricultura e historia natural, muchas de ellas enriquecidas con donativos procedentes de personalidades de diferentes partes de la Isla. En 1889 solicitó a París aparatos, instrumentos y ejemplares de historia natural que debieron llegar por esas fechas a fín de «aunar las necesidades de la enseñanza con la adquisición de los aparatos más perfectos y más en armonía con los modernos adelantos científicos» ${ }^{30}$. Los datos estadísticos obtenidos acerca de este instituto revelan, por ejemplo, que en 1882 el gobierno le asignó la cantidad de 19.350 pesos, reduciéndolo en 1885 a 13.400. Sin embargo esto parece no haber afectado grandemente a la institución, pues cobraba por derechos académicos, de inscripción o matrículas, de grados, etcétera, una respetable suma. Así, por ejemplo, ingresó por estos conceptos la cantidad de 59.831 pesos en el periodo correspondiente a los años 1882 hasta 1889.

27 Torralbas, J. I. (1891) «Elogio al Iltmo. Sr. D. Nicolás José Gutiérrez». Anales de la Academia de Ciencias Médicas, Físicas y Naturales de La Habana, t. 28, pp. 471-479.

28 Para un estudio de los Institutos de Segunda Enseñanza de la Isla pueden consultarse las Memorias, Discursos y Programas que se publicaron a lo largo del siglo XIX y parte del XX.

29 GONZÁLEZ LÓPEZ, R. M. (1990) Juan Cristóbal Gundlach. Apuntes biográficos. La Habana, Editorial Academia.

30 PiChARdo y PICHARdo, G. (1889) Memoria del curso académico de 1888 a 1889. Habana, Imprenta del Gobierno y Capitanía General, p. 24. 


\section{MERCEDES VALERO GONZÁLEZ Y ARMANDO GARCÍA GONZÁLEZ}

Como en el caso de los de las escuelas religiosas, perduraron hasta 1959 y fueron trasladados por esa fecha hacia otras instituciones, con la desaparición de este tipo de colegio. Desempeñaron un encomiable trabajo en la labor docente, no solo por las actividades propias que realizaron, sino también porque tuvieron incorporados numerosos colegios privados en toda la Isla.

\section{LOS MUSEOS Y GABINETES EN ESCUELAS RELIGIOSAS.}

Los museos de ciencias naturales también debieron su avance, en cierta medida, a la labor efectuada, con fines educativos, en los institutos docentes como las Escuelas Pías de los escolapios y las de los jesuitas (Colegio de Belén, etcétera), centros que seguían la tradición de este tipo de instituciones constituidas en naciones europeas.

Los colegios de los escolapios habían alcanzado prestigio en España desde la segunda mitad del siglo XVIII con la instauración de la Orden Calasancia. Algo parecido sucedía en otros países europeos. En las primeras décadas de la centuria decimonónica grupos de escolapios catalanes llegan al continente americano con el objetivo de fundar este tipo de centros de enseñanza. Por eso, aunque el establecimiento de tales centros se ordenó por Real Cédula del 24 de noviembre de 1852, ya desde 1815 existen escuelas pías en la Isla. Una de ellas fue la Escuela Calasancia, fundada en este último año por el padre Ramón de Otero, dedicada a la primera y segunda enseñanza. Posee el mérito de haber dado origen a los colegios de San Cristóbal de Carraguao, del Salvador y de San Fernando. Luego de diversas vicisitudes se logró establecer, en 1857, una escuela Pía en Guanabacoa y otra en Puerto Príncipe. La de Guanabacoa fue abierta en realidad como Escuela Normal de Profesores ${ }^{31}$, la primera que hubo en la Isla, aunque conjuntamente con ella, comenzó a funcionar la Escuela práctica, a la que asistirían los alumnos de éste y otros municipios.

En ese mismo año de 1857 llegó a Cuba el padre Francisco Clerch y comenzó a plasmarse el Museo de Historia Natural y los Gabinetes de Física, Matemática y Química. Clerch formaba parte de una importante comunidad de catalanes que desempeñó destacada labor docente y científica en su país. Su personalidad se perfiló en esencia como naturalista, de ahí su interés por el montaje de estos gabinetes. Hay que señalar que si bien no fue el único, ni el principal coleccionador, al parecer sí fue el iniciador, dándoles un carácter especial. Mostró evidente preferencia por los moluscos (conchas) y minerales, clasificando muchos ejemplares.

31 Esta Escuela Normal se debió en gran medida a la insistencia del capitán y gobernador general José Gutiérrez de la Concha, quien desde 1880 pretendía crear este tipo de institución en Cuba. CALASANZ BAU, P. (1957) Historia de las Escuelas Pías en Cuba durante el primer siglo de su establecimiento 1857-1957. Habana. Los datos que siguen respecto a estas escuelas son tomados fundamentalmente de este autor. 
Con la creación de estos gabinetes y museos se esperaba dotar también al colegio, además de con muestras de ciencias naturales, del mejor instrumental posible de física, química, matemáticas y astronomía; e incluso, se aspiraba a instalar en el colegio un Observatorio de Geodinámica, llegándose a pensar en invitar para ello al eminente escolapio italiano padre Sechi. En 1859 se establecieron los primeros gabinetes que llegaron a tener amplias colecciones mineralógicas, plantas y maderas útiles, especímenes animales, como mamíferos, peces, moluscos (conchas), insectos, esponjas. Igualmente se adquirieron instrumentos para la enseñanza de la física y la química, comprados en París.

La actividad de este museo tuvo asimismo carácter internacional al enviar un total de 482 muestras de minerales a la Exposición Universal de París, en 1867. También en 1888 participó en la Exposición de Barcelona enviando ejemplares; en esta última a través del padre Pío Galtés, quien había llegado a Cuba en 1873 y ocupó la dirección de la Academia Calasancia y con posterioridad el rectorado de los escolapios de Guanabacoa. Entre los importantes estudios que llevó a cabo se encuentra el de un ejemplar de palma fosilizada, traída de Camagüey por el padre Clerch. Dicho trabajo obtuvo medalla de oro y merecidos elogios en la aludida Exposición de Barcelona. Galtés realizó además de estos trabajos de fitopatología, otros de antropología y geología y hasta escribió libros de texto para las escuelas. Al igual que Clerch, mantuvo la condición prestigiosa del Museo de Ciencias Naturales y de sus interesantes colecciones, así como vínculos de trabajo con naturalistas como Felipe Poey y Juan Cristóbal Gundlach.

Aunque las escuelas pías adquirían fondos de diversas fuentes, como las colectas y donaciones y cobro de matrículas y de los municipios para manutención de los alumnos, no siempre navegó en la abundancia, y llegó a afrontar verdaderos problemas económicos, que hicieron por ejemplo que cerrara su Escuela Normal en 1868. Según algunos autores la guerra no tuvo mucha influencia en este sentido, sino la falta de recursos económicos. Pero esto habría que investigarlo. Aunque es posible, si se tiene en cuenta que, a partir de 1869 , continuó funcionando como escuela práctica de primera y segunda enseñanza. Labor que desplegó, manteniendo y enriqueciendo sus gabinetes, hasta 1958.

También siguió este tipo de tradición científica el Colegio de Belén perteneciente a los jesuitas. El mismo se fundó en 1854, en el convento de igual nombre, por la Compañía de Jesús. Con fines educativos se creó en el aludido colegio un observatorio fundamentalmente meteorológico, aunque también servía para práctica, mediciones magnéticas, sísmicas y observaciones astronómicas. Este observatorio, dada la posición geográfica de Cuba, se especializó en el estudio de los ciclones tropicales, lo que lo convirtió en uno de los más importantes del mundo en lo que a este tema se refiere, gracias a la labor destacada del padre Benito Viñes. 
El colegio contó desde 1857 con un gabinete de física y química y un pequeño museo para el estudio práctico de las ciencias naturales, cuyos instrumentos, en función de la enseñanza, permitían que las clases no se limitaran a cuestiones teóricas. En el caso del observatorio, el instrumental allí dispuesto propició que día a día se pudieran efectuar análisis e ir acumulando datos acerca de la presión atmosférica, temperatura, humedad relativa y tensión del vapor de agua contenido en la atmósfera. En general casi todos los aparatos adquiridos en 1862 fueron fabricados en Inglaterra, debido a las gestiones del padre Sechi, del Observatorio del Colegio Romano. La adquisición de estos instrumentos trajo como consecuencia la necesidad de construir un nuevo local en el Colegio. Las obras, costeadas por el propio Colegio, quedaron terminadas en ese mismo año y colocados los mencionados instrumentos. Este período de acondicionamiento, organización y equipamiento sentó las bases para el futuro florecimiento del observatorio que se hizo más evidente con la presencia del padre Viñes entre 1870 y 1893 . Viñes también adquirió instrumentos - para las observaciones magnéticas - en el Observatorio de Kew, gracias a las gestiones del R.P. Perry.

Las observaciones y estudios realizados en el Colegio de Belén rebasaron el marco de la enseñanza para ofrecer un valioso servicio nacional e internacional, sobre todo en relación con los ciclones y otros fenómenos atmosféricos, e incluso se idearon en él instrumentos, como el Ciclonoscopio de las Antillas, fabricado por el propio Viñes para la aplicación práctica de su ley acerca de los ciclones. Sus publicaciones y las del observatorio fueron remitidas a bibliotecas, centros oficiales, sociedades científicas y observatorios de diversos países, obteniendo premios en exposiciones universales como las de Filadelfia en 1876, París en 1878, Barcelona en 1888 y Chicago en 1893. Nuevo arreglos se hicieron en el edificio en 1896, costeados igualmente por el propio Colegio, y su labor se mantuvo en alto nivel durante el siglo XIX y primeros años del XX, siendo desplazado en esta última centuria por el Observatorio Nacional, si bien mantuvo su actividad hasta 1961. Aunque padeció en ocasiones dificultades económicas, el Colegio de Belén y su Observatorio lograron pervivir a pesar de las crisis políticas y sociales que se produjeron a lo largo del siglo e incluso sobrevivió a las dos guerras independentistas. Gozó de la confianza del gobierno español durante estos conflictos - téngase en cuenta el servicio prestado al transporte naval comercial y de guerra - no sólo por estar constituido por jesuitas españoles sino también por la inestabilidad y decadencia del Observatorio Físico Meteórico, que sólo funcionó algunos años ${ }^{32}$.

32 VAlero GonZÁLEZ, M. (1988) «El observatorio del Colegio de Belén en el siglo XIX». Anuario, 1. Opus cit., pp. 200-217. Véase también a RAMOS GUADALUPE, L.E. Benito Viñes. Estudio biográfico La Habana, Editorial Academia (en prensa). 


\section{OTROS GABINETES EN INSTITUCIONES CIENTÍFICAS CUBANAS}

Durante el siglo XIX se crearon igualmente otras instituciones científicas que establecieron gabinetes, compuestos por instrumentos para llevar a cabo la realización de sus actividades, que incluían muchas veces o casi siempre la posibilidad de la enseñanza a través de diferentes cátedras. Pueden mencionarse, por ejemplo, el aludido Observatorio Físico Meteórico y el Laboratorio Histobacteriológico e Instituto de Vacunación Antirrábica, ambos de La Habana. El primero propuesto en 1852 por el catedrático de Historia y Geografía José María de la Torre al Gobernador de la Isla, halló eco en Andrés Poey, quien elaboró un informe en 1855 para su creación. Apoyado por la Junta de Fomento y sobre todo por miembros de la Sociedad Económica de Amigos del País, como Felipe Poey, Antonio Bachiller y otros, el proyecto obtuvo la aprobación del gobierno el 31 de octubre de 1856, cediéndole éste algunos fondos a la mencionada Sociedad para emprender la obra ${ }^{33}$.

Diversas dificultades y el hecho de que la persona encargada para dirigir el Observatorio, Andrés Poey, dedicó algunos años al estudio de esa disciplina en Inglaterra, Francia, Alemania y España, hicieron que fuese establecido en la azotea del edificio de la Sociedad Económica. No obstante se habilitó por parte del gobierno el sueldo para el personal que habría de atenderlo, así como de una cantidad de cuatro mil pesos para la compra de instrumentos adecuados y mil anuales para su conservación; así como se estableció la publicación de un anuario para distribuirlo a las corporaciones científicas de España y del extranjero ${ }^{34}$. El interés que se manifiesta en esa época por parte del gobierno insular pudo deberse a que aún el Colegio de Belén no había adquirido el prestigio que luego obtuvo con la presencia de Viñes a partir de 1870. El caso es que la cátedra proyectada por Andrés Poey para impartir la meteorología y formar discípulos no dio los resultados esperados, pues no se presentaron alumnos. La ausencia de este científico, comisionado en otros países como México y Francia para la creación de un observatorio en un caso y de estudios en el otro, le hicieron desatender la labor en la institución cubana. De ahí que se le sustituyera en 1869 acusado de «moroso en el cumplimiento de su deber» ${ }^{35}$. Los instrumentos del Observatorio pasarían posteriormente, en 1875, a las Escuelas Generales Preparatorias o Profesionales, dedicadas a la enseñanza técnica. Allí funcionó con altibajos el Observatorio hasta 1887, fecha en que se trasladó a la Universidad, donde dejó de funcionar y donde los instrumentos se deterioraron gradualmente. La falta de un local adecuado y la carencia de recursos económicos fueron factores decisivos en su extinción.

33 DíAZ ARgüElles, N. (1988) «El Observatorio Físico Meteórico de La Habana». Anuario, 1 Opus cit., pp. 218-247.

34 Ibidem.

35 Ibidem, p. 229. 
También tuvo un gabinete el Laboratorio Histobacteriológico. Este instituto, creado gracias a las actividades de un grupo de médicos cubanos y españoles, entre los que se encontraban Juan Santos Fernández, Carlos J. Finlay, Claudio Delgado, Diego Tamayo y otros, se inauguró el 8 de mayo de 1887, y entre sus muchos logros realizó determinada labor docente en el campo de la bacteriología. El laboratorio funcionó realmente en la casa de Juan Santos Fernández y no contó con apoyo financiero por parte del gobierno. Sin embargo fue reconocido y consultado por éste, debido al aporte que realizó en el campo bacteriológico. La labor del Observatorio se mantuvo hasta $1960^{36}$.

\section{ALGUNAS CONSIDERACIONES HISTORIOGRÁFICAS}

El tema del coleccionismo científico cubano ha sido abordado por algunos autores nacionales, pero no lo suficiente como para permitir que se pueda hacer una evolución global de esta tradición y de su vinculación y aplicación con las ciencias, la enseñanza y otras manifestaciones culturales. Algunos investigadores han dedicado esfuerzos en este sentido, dando a la publicidad algunos trabajos o escribiendo otros que se mantienen inéditos. Uno de estos últimos, es el estudio de Armando Rangel Rivero, Los museos de ciencias en Cuba en el siglo XIX, presentado como Diploma de Grado en el Instituto de Museología hace más de una década. El mismo recoge diferentes datos históricos, colecciones más importantes y otros, mas no aborda de manera conveniente la vertebración entre estas instituciones ni las complejas relaciones sociopolíticas y económicas que la impulsaron o hicieron caer. Sin embargo, constituye uno de los pocos trabajos que existen sobre el tema, por lo que ha sido utilizado como material docente en el Centro de Conservación, 'Museología y Restauración de La Habana.

En 1974, en su libro Antonio Parra en la ciencia hispanoamericana del siglo XVIII, Armando García González aborda el coleccionismo realizado en Cuba en el periodo de la Ilustración, a través de la figura de este portugués, llegado a La Habana como militar español y radicado aquí durante treinta años. En este estudio el autor no sólo analiza el gabinete de Parra -el primero de importancia en la Isla—, sino también su vinculación con el coleccionismo español de la época, desde el punto de vista institucional.

Posteriormente, este autor, conjuntamente con Rangel Rivero, publicó en 1991, en la revista madrileña Asclepio, un estudio sobre el primer «museo» institucionalizado en Cuba, el Museo Anatómico de La Habana, fundado en 1823. Museo que se encar-

36 DíAZ ARGÜELLES, N. (1988) «Breve Bosquejo histórico del Laboratorio Histobacteriológico e Instituto de Vacunación Antirrábica de La Habana». Anuario, 1 Opus cit., pp. 170-199. 
gó, entre otras cosas, de la enseñanza de la anatomía, la cirugía y la obstetricia. El mismo fue un importante antecedente y desde él se llevaron a cabo los diversos intentos para fundar una Academia de Ciencias en esa ciudad. Sobre el Museo de esta institución, establecido en 1874, García González ha publicado el trabajo Historia del Museo de la Real Academia de Ciencias Médicas, Físicas y Naturales de La Habana, que incluye además una breve referencia a varios de los museos y gabinetes creados anteriormente en Cuba.

También de manera colateral, la investigadora Rosa María González, ha abordado, en relación con la figura de Felipe Poey y Juan C. Gundlach, los gabinetes y museos con los cuales estos estuvieron íntimamente relacionados, a saber los de la Universidad, la Sociedad Económica y el Instituto de Segunda Enseñanza ${ }^{37}$. Asimismo habría que mencionar los artículos de Mercedes Valero, Nancy Díaz Argüelles y Leida Fernández, citados en este trabajo, así como el estudio monográfico de Luis Enrique Ramos sobre Benito Viñes, que trata acerca del Colegio de Belén. Sin embargo faltan los estudios monográficos sobre los museos y gabinetes de las citadas instituciones. Tampoco se han realizado estudios de aquéllos que pertenecieron a otros centros docentes como los Institutos de Segunda Enseñanza de las provincias, las Escuelas Pías, el Seminario de San Carlos y San Ambrosio y otros museos y gabinetes decimonónicos, a los cuales aludimos en este panorama preliminar del coleccionismo científico cubano, que más bien intenta estimular su estudio que brindar aportes importantes.

Hay que destacar, no obstante, que se han realizado estudios específicos sobre colecciones y exponentes particulares, pertenecientes a algunas de estas figuras, como las que corresponden a Gundlach, Poey, Carlos de la Torre, Luis Montané, Miguel Rodríguez Ferrer y otros. Todo lo cual merecería al menos, una relación historiográfica que tampoco se ha llevado a efecto o no conocemos. De manera similar se nota la ausencia de análisis sobre el coleccionismo llevado a cabo por personalidades decimonónicas como Sebastián Alfredo de Morales, Rafael Arango y Molina, Manuel de Paz y Morejón y otros, hallándose sólo meras referencias; si bien en ocasiones eso es todo lo que existe. Pero evidentemente habría que explorar en lugares que ofrecen riqueza documental al respecto, como los Archivos Nacional y del Museo de Ciencias Naturales de Madrid, el de La Habana y otros. Asimismo podrían resultar interesantes los estudios de colecciones y ejemplares cubanos que existen en museos extranjeros.

Desde el punto de vista internacional no conocemos trabajo alguno que se haya ocupado de esta temática sobre Cuba. Algunos estudios llegan a ser, sin embargo, significativos, sobre todo los efectuados en España, por la estrecha relación de ésta con la Isla y más en el período colonial, que tratan tangencialmente el coleccionismo

37 Véase GONZÁLEZ LóPEZ, R.M. (1990). Juan Cristóbal Gundlach. Opus cit. Y de la misma autora, Vida y obra de Felipe Poey. (En prensa). 


\section{MERCEDES VALERO GONZÁLEZ Y ARMANDO GARCÍA GONZÁLEZ}

efectuado en la península. Pueden destacarse por ejemplo, las obras siguientes: Franco Dávila y el Real Gabinete de Historia Natural de María de los Angeles Calatayud (1988), que trata de este personaje y de su labor en relación con el aludido gabinete de Madrid en el siglo XVIII; la monografía de Javier Puerto (1992) Ciencia de cámara. Casimiro Gómez Ortega (1741-1818), el científico cortesano, quien fuera director del Jardín Botánico de Madrid; el de J.A. Barreiro (1944), El Museo Nacional de Ciencias Naturales de Madrid. También son fuentes de abundantes referencias al coleccionismo científico ilustrado y decimonónico, las obras que tratan sobre expediciones. Entre ellas podemos citar la que se refiere a la expedición de Mopox, y que con el título de Cuba Ilustrada. Real Comisión de Guantánamo 1796-1802, publicó un colectivo de autores españoles (1991). Igualmente hay que destacar la que se refiere a la expedición de Malaspina, titulada La ilustración española y el conocimiento del Nuevo Mundo, de Andrés Galera (1988), que aborda la expedición al Pacífico, así como la denominada Crónica de una expedición romántica al Nuevo Mundo, escrita por Miguel Angel Puig-Samper, La Flora de Guatemala, de Luis Maldonado (1996), y otros diversos artículos que harían onerosa esta relación.

Un análisis a priori del tema permite sugerir una posible periodización que facilite el estudio sobre los gabinetes y museos de ciencias del siglo XIX y grosso modo para el siglo XX. Esta pudiera abarcar una fase de «coleccionismo privado o individual» realizado por particulares desde mediados del siglo XVIII hasta 1958, pues esta actividad no se detuvo en el diecinueve, sino que perdurará hasta el XX, destacándose figuras como Mario Sánchez Roig, Miguel L. Jaume, Abelardo Moreno y otros en la primera mitad de esta última centuria. Y que se caracterizó porque facilitó el desarrollo de obras de carácter científico, aunque en ocasiones también favoreció la docencia.

. La segunda fase o etapa representada por el «coleccionismo institucionalizado de relativa estabilidad», a partir de la creación en 1823 del primer museo, el Museo Anatómico de La Habana, que perdura hasta 1863, fecha en la cual se consolidan los gabinetes y museos de la Universidad de La Habana por las reformas educacionales llevadas a cabo en ese año. Esta fase podría incluir aquellos que se crean en torno a estas fechas, que realizaron trabajo docente de forma tangencial, como las Escuelas Pías (1859) y el Colegio Belén (1857) en sus primeros tiempos, las escuelas agrícolas e institutos químicos (década del cuarenta y cincuenta), etcétera.

Una tercera fase de «coleccionismo institucionalizado más estable», representada por los gabinetes de los Institutos de Segunda Enseñanza (1863), Escuelas Pías y Colegio de Belén en su segunda etapa, así como los de la Universidad de La Habana, a partir de 1863. Todos dedicados en mayor o menor medida a la enseñanza. Y junto con ellos el Museo de la Real Academia de las Ciencias Médicas, Físicas y Naturales en 1874, que si bien no estuvo dedicado a la enseñanza, le sirvió en ocasiones de apoyo. 
Una cuarta fase, que podríamos llamar «estacionaria desde el punto de vista institucional», abarcaría desde 1900 a 1958, donde no existen significativos incrementos de museos y gabinetes en relación con el auge adquirido durante el siglo XIX. Lo cual no quiere decir que no se instauren algunos, como fueron el Museo Antropológico «Montané» y el «Felipe Poey», ambos creados a partir de colecciones pertenecientes a la Universidad y a la Academia de Ciencias de La Habana.

\section{ALGUNAS CONCLUSIONES GENERALES}

Como es posible constatar en esta panorámica y no completa visión de museos y gabinetes del siglo XIX cubano, el coleccionismo científico siguió al parecer dos líneas generales: una representada por el coleccionismo individual de personalidades amantes de las ciencias que construyeron sus colecciones tras paciente y dedicada labor; la otra, de manera institucional. En el primer caso, el coleccionismo científico tenía sus antecedentes en el efectuado en el siglo XVIII no siempre por especialistas sino también por simples aficionados. Esta actividad continuó de manera parecida en la centuria decimonónica. Muchas de estas colecciones fueron donadas o vendidas a los museos y gabinetes que se crearon de manera institucional. Las mismas pertenecieron no sólo a figuras cubanas y españolas sino también a personalidades de otras nacionalidades que residieron en Cuba. La visita de estas personalidades a Cuba facilitó que muchas especies y muestras científicas se incorporaran a museos y gabinetes europeos y americanos. Esta actividad se acentuó con la labor de intercambio efectuada por sus propietarios, el envío a exposiciones internacionales, y el deseo de clasificar nuevas especies encontradas, etcétera.

En el caso institucional parece destacarse un mayor desarrollo en aquellos gabinetes y museos que realizaron determinada labor en la enseñanza, o al menos, su intención favoreció la compra o adquisición de piezas naturales, muebles e instrumentos que en diversos casos impulsaron la enseñanza de algunas ciencias en Cuba. Existen sin embargo excepciones de acuerdo con los períodos, recursos económicos y desarrollo de las instituciones que los crearon. Así, algunos que comenzaron de manera significativa, como el Museo Anatómico, degeneraron luego de algunos años, mientras otros ni siquiera tuvieron un papel relevante en ese sentido, como fue el caso del gabinete del Observatorio Físico Meteórico y otros.

Los gabinetes y museos de instituciones no dedicadas a la enseñanza, como los de la Sociedad Económica y la Real Academia de Ciencias, difieren sin embargo: mientras que el primero apenas si llegó a ser reconocido, el segundo alcanzó el máximo desarrollo de este tipo de institución en Cuba, siendo visitado además por nacionales y extranjeros. Sostuvo, a través de la Academia, determinado intercambio de muestras, donaciones, etcétera, con otras instituciones similares foráneas. 
Aunque la Universidad de La Habana aglutinó en la segunda mitad del siglo XIX muchos de los gabinetes pertenecientes a extintas instituciones (el Museo Anatómico, el gabinete del Instituto de Investigaciones Químicas, el del Observatorio Físico Meteórico y otros) la realidad es que adoleció de locales apropiados y los recursos económicos adecuados para mantenerlos en una óptima conservación. Por otra parte muchos llegaron a la Universidad ya bastante deteriorados. No obstante ello, sólo algunos de este centro docente, de los Institutos de Segunda Enseñanza y las Escuelas Pías, así como de la Academia de Ciencias, rebasan el siglo XIX para mantenerse en un estado decoroso en la siguiente centuria.

El apoyo gubernamental (insular y peninsular) desde el punto de vista económico no fue regular en el período señalado, hallándose de forma más o menos presente hasta la década del sesenta del pasado siglo. Esto hizo que cerraran instituciones o decayeran otras de verdadera importancia científica para el país y aun para la propia España, como fueron el Instituto de Investigaciones Químicas de La Habana, el Observatorio Físico Meteórico y otros. Y por supuesto, los museos y gabinetes pertenecientes a estas instituciones corrieron igual suerte. A partir de la Guerra de los Diez Años, y tal vez antes, debido también a la propia crisis económica política y social que presentaba España, los recursos son prácticamente nulos, si bien se permiten la creación de instituciones - aún en plena guerra-como fueron la Sociedad Antropológica de la Isla de Cuba (1877-1892), el Laboratorio Histobacteriológico y el Instituto de Vacunación Antirrábica (1887) entre otros.

A pesar de los estudios mencionados en este artículo, lo cierto es que aún falta por abordar una buena parte de los museos y gabinetes que existieron el siglo XIX en Cuba, así como aquellos que se constituyeron en otros países, lo que permitiría realizar análisis comparativos, con vistas a una mejor comprensión del desarrollo y los aportes brindados por tales instituciones. 